\title{
Assessment of Serum Uric Acid Levels in Patients with Acute Myocardial Infarction
}

\author{
Manjiri Ravindra Kulkarni ${ }^{\odot}$ \\ Assistant Professor, Department of Medicine, RKDF Medical College Hospital \& Research Centre, Bhopal, Madhya Pradesh, India.
}

\section{Abstract}

Background : Aim of the study was to discover if there is the efficacy of serum uric acid in the prognostication of myocardial infarction subjects. Subjects and Methods: A total of 200 subjects were incorporated into the research. Of them, 74 patients had ST- elevated myocardial infarction, as in 26 subjects they were diagnosed with non-ST elevation myocardial infarction. Of the total of 100 subjects in the study group, there were 70 males and 30 females. A total of 100 healthy individuals as a control group were also incorporated in the study. Serum uric acid was measured on day 0, 3, 7 as well on day 30 of MI. Results: Serum uric acid was calculated on day 0, day 3, and day 7 and on day 30 of the myocardial infarction in the case study group. The mean uric acid levels on day 0 were found to be $6.32 \pm 1.45 \mathrm{mg} / \mathrm{dl}$, mean uric acid level on day $3 \mathrm{was}$ found to be $5.98 \pm 0.98 \mathrm{mg} / \mathrm{dl}$, mean uric acid level on day 7 was found to be $5.14 \pm 2.18 \mathrm{mg} / \mathrm{dl}$ and mean uric acid level on day 30 was found to be $4.98 \pm 0.44 \mathrm{mg} / \mathrm{dl}$. Conclusion: Serum uric acid stages are elevated in subjects of acute MI in contrast to standard well individuals. Subjects with higher Serum uric acid levels have an elevated probability of transience and it can be measured as a marker of appalling prediction.

Keywords: Cardiac Muscle, Myocardial Infarction, Uric acid Level

Corresponding Author: Manjiri Ravindra Kulkarni, Assistant Professor, Department of Medicine, RKDF Medical College Hospital \& Research Centre, Bhopal, Madhya Pradesh, India.

E-mail: lionravindrakulkarni@yahoo.com

\section{Introduction}

Myocardial infarction (MI) is the disruption of blood supply to a fraction of the heart, origins heart cells to expire. ${ }^{[1]}$ The most ordinary cause underlying an incident of acute myocardial infarction is Coronary Artery Disease with attrition or break of a plaque causing fleeting or inequitable or whole arterial occlusion. Coronary artery disease is an important source of cardiovascular death globally, with $>4.5$ million deceases going on in the globe. ${ }^{[2,3]}$ Standard signs of acute MI comprise unexpected chest pain characteristically burning to the left arm or left side of the neck, breathlessness, vomiting, palpitations, sweating, and anxiety. ${ }^{[4]} \mathrm{MI}$ can happen devoid of any counsel indications, which are described as silent MI. Several may be connected with "atypical' signs, for instance, heartburn, nausea, or abrupt dizziness and sweating. ${ }^{[5]}$ Hyperuricemia in coronary occlusive disease has been known and a transient elevation of serum uric acid has been reported in acute MI. However, some authors have demonstrated a fall in the serum uric acid levels during the first two days 9 of hospitalization. They have also reported an association among the decrease in serum uric acid levels and serum lactate dehydrogenase. ${ }^{[6]}$ Uric acid is an indicator assess for prediction in subjects with AMI. Different apparatus had assumed for the damaging things of hyperuricemia with unpleasant cardiovascular results, comprises endothelial dysfunction, platelet tackiness and aggregation, and enhancement of vasoconstrictor effects. ${ }^{[7]}$ Uric acid may function as an antioxidant, and probably principal antioxidants in plasma but, in assured circumstances, it can also act as a pro-oxidant. ${ }^{[8]}$ As a result there is a requirement for additional research in this matter to identify the definite position of antioxidants in myocardial infarction and too they have any predictive importance. Also, the exact position of serum uric acid in the pathogenesis, clinical diagnosis and prognosis have not been evaluated in myocardial infarction. Therefore present research aims to discover is several efficacy of serum uric acid in the prognostication of MI subjects.

\section{Subjects and Methods}

The subjects analyzed as ST section elevation acute myocardial infarction (STEMI) or non-ST segment elevation acute myocardial infarction (NSTEMI) on the origin of clinical account assessment, ECG changes, and biochemical markers 


\begin{tabular}{|l|l|l|}
\hline \multicolumn{3}{|c|}{ Table 1: Age Distribution of the Case and Control Groups } \\
\hline Age (years) & $\begin{array}{l}\text { No. of subjects in the } \\
\text { case group }\end{array}$ & $\begin{array}{l}\text { No. of individ- } \\
\text { uals in control } \\
\text { groups }\end{array}$ \\
\hline$<50$ & 10 & 18 \\
\hline $50-60$ & 20 & 38 \\
\hline $60-70$ & 42 & 34 \\
\hline $70-80$ & 16 & 10 \\
\hline$>80$ & 12 & - \\
\hline Total & 100 & 100 \\
\hline
\end{tabular}

were enrolled in this study. A total of 200 subjects were incorporated into the research. Seventy-four subjects had STEMI, while in 26 subjects they were diagnosed with NSTEMI. Of the total of 100 subjects in the study group, there were 70 males and 30 females. A total of 100 healthy individuals as a control group were also incorporated in the study. Complete history and clinical assessment were performed. All subjects undergo regular investigations with complete blood counts, renal function tests, liver function tests, ECG, chest X-ray and echocardiogram. The subjects were recalled to their discharge. Serum uric acid was measured on day $0,3,7$ as well on day 30 of MI. The analysis was performed using spss version 15 .

\section{Results}

The current research was done on 100 subjects diagnosed with acute MI, accessible to the medical hospital within 24 hours of the onset of the symptoms. A total of 66 subjects were thrombosed whereas due to delayed presentation 8 subjects were not. The control group consisted of 100 healthy individuals without any cardiac problem. The age range for the individuals in the control group was from $35-80$ years. The mean age was found to be $54.3 \pm 11.7$ years in the control group. The highest records of subjects were in the age group of 50 to 60 years. In the study group, the age range was from $45-90$ years. The age range in the case group was found to be $61.5 \pm 16.1$ years. The maximum numbers of subjects in the case group were in the age group of 60 to 70 years. [Table 1]

Serum uric acid was measured on day 0 , day 3, and day 7 and on day 30 of the myocardial infarction in the case study group. The mean uric acid levels on day 0 were found to be $6.32 \pm 1.45 \mathrm{mg} / \mathrm{dl}$, mean uric acid level on day 3 was found to be $5.98 \pm 0.98 \mathrm{mg} / \mathrm{dl}$, mean uric acid level on day 7 was found to be $5.14 \pm 2.18 \mathrm{mg} / \mathrm{dl}$ and mean uric acid level on day 30 was found to be $4.98 \pm 0.44 \mathrm{mg} / \mathrm{dl}$. When the statistical analysis was done on the result obtained, in between the values obtained from the control group to that on the day of admission, the differences were found to be statistically significant. $(\mathrm{p} \leq 0.05)$ When the mean values of serum uric acid levels were compared from day 0 to day 30 , the level of serum uric acid was found to be decreasing. When the values of mean serum uric acid levels were measured between the control group and that of on day 30 , the dissimilarity was not established to be statistically significant.

\section{Discussion}

Researchers revealed that uric acid may be a threat to cardiovascular diseases. ${ }^{[9]}$ Clinical types of research have High serum uric acid causes rising platelet reactivity arbitrating inflammation and stimulus of smooth muscle cell propagation, which perhaps worsens acute thrombosis. ${ }^{[10]}$ There is proof that high uric acid is a pessimistic predictive feature in subjects with acute myocardial infarction. ${ }^{[11]}$ However certain other studies have stated that any relationship among the levels of uric acid and transience from AMI is only owing to the union of uric acid with previous risk factors and uric acid by itself does not have any alliance with the mortality rate of MI. The current research was performed on 100 subjects of acute MI. Total of hundred age and gender coordinated vigorous controls were also assess for judgment. Mikus, ${ }^{[12]}$ finished comparable findings. while, Sokhanvar, ${ }^{[13]}$ et al, accounted that there are augmentin SUA levels as the time proceeds. Significant superior level of SUA in subjects of AMI on the day of an entrance as a contrast to controls. SUA slowly diminished with the moment in subjects of MI \& on day 30 levels were analogous to that in the control group. Therefore, subjects had superior SUA levels on day 0 perhaps since of AMI. Comparable outcomes examined in research by Kojima, ${ }^{[14]}$ et al Nadkar, ${ }^{[15]}$ et al, also found that SUA levels are superior in subjects with acute MI as a contrast to fit gender and age coordinated controls.

\section{Conclusion}

Serum uric acid levels are advanced in subjects of acute MI in contrast to standard well people. Subjects with superior Serum uric acid levels have an elevated probability of death, which can be measured as the pointer of poor prognosis.

\section{References}

1. Farb A, Tang AL, Burke AP, Sessums L, Liang Y, Virmani R. Sudden coronary death: frequency of active coronary lesions, inactive coronary lesions, and myocardial infarction. Circulation. 1995;92(7):1701-1710. Available from: https: //doi.org/10.1161/01.cir.92.7.1701.

2. Ambrose JA, Singh M. Pathophysiology of coronary artery disease leading to acute coronary syndromes; 2015. Available from: https://doi.org/10.12703/p7-08.

3. Libby P, Theroux P. Pathophysiology of Coronary Artery Disease. Circulation. 2005;111(25):3481-3488. Available from: https://dx.doi.org/10.1161/circulationaha.105.537878. 
Table 2: Serum Uric Acid Level in Subjects and Control Group on Day 0, 3, 7 And 30

\begin{tabular}{llll|l}
\hline Groups & Day 0 (mg/d) & Day 3 (mg/dl) & Day 7 (mg/dl) & Day 30 (mg/dl) \\
\hline Case group & $6.32 \pm 1.45$ & $5.98 \pm 0.98$ & $5.14 \pm 2.18$ & $4.98 \pm 0.44$ \\
\hline Control group & $4.85 \pm 0.86$ & $4.85 \pm 0.86$ & $4.85 \pm 0.86$ & $4.85 \pm 0.86$ \\
\hline P value & $<0.001$ & $<0.05$ & $<0.05$ & 0.056 \\
\hline
\end{tabular}

4. Malik MA, Khan SA, Safdar S, Taseer IUH. Chest Pain as a presenting complaint in patients with acute myocardial infarction (AMI); 2013. Available from: https://dx.doi.org/10. 12669/pjms.292.2921.

5. Cervellin G, Rastelli G. The clinics of an acute coronary syndrome. Ann Translational Med. 2016;4:4-8.

6. Fenech G, Rajzbaum G, Mazighi M, Blacher J. Serum uric acid and cardiovascular risk: State of the art and perspectives. Joint Bone Spine. 2014;81(5):392-397. Available from: https: //dx.doi.org/10.1016/j.jbspin.2014.01.008.

7. Maruhashi T, Hisatome I, Kihara Y, Higashi Y. Hyperuricemia and endothelial function: From molecular background to clinical perspectives. Atherosclerosis. 2018;278:226-231. Available from: https://dx.doi.org/10.1016/j.atherosclerosis.2018. 10.007 .

8. Vertuani S, Angusti A, Manfredini S. The Antioxidants and Pro-Antioxidants Network: An Overview. Curr Pharm Des. 2004;10(14):1677-1694. Available from: https://dx.doi.org/10. 2174/1381612043384655.

9. V P, Banupriya A. Serum uric acid levels in acute myocardial infarction. Int J Adv Med. 2017;4(4):1010-1010. Available from: https://dx.doi.org/10.18203/2349-3933.ijam20173222.

10. Mahajan RD, Gurtoo A, Singh R. Evaluation of biochemical parameters in subjects of myocardial infarction. Int Jour of Biomed Res. 2011;2(5):272-281.

11. Llull L, Amaro S, Ángel Chamorro. Administration of Uric Acid in the Emergency Treatment of Acute Ischemic Stroke. Curr Neurol Neurosci Rep. 2016;16(1):4-4. Available from: https://dx.doi.org/10.1007/s11910-015-0604-7.

12. Mikus F, Hyperuricemia. Beitrage zur Rheumatologie. 1972;18:74-74.

13. Sokhanvar S, Maleki A. Blood uric acid levels according to cardiovascular disease risk factors in subjects with myocardial infarction. Iranian Heart J. 2007;8(1):43-45.

14. Kojima S, Sakamoto T, Ishihara M, Kimura K, Miyazaki S, Yamagishi M, et al. Prognostic Usefulness of Serum Uric Acid After Acute Myocardial Infarction (The Japanese Acute Coronary Syndrome Study). Am J Cardiol. 2005;96(4):489495. Available from: https://dx.doi.org/10.1016/j.amjcard. 2005.04.007.

15. Nadkar M, Jain V. Serum uric acid in acute myocardial infarction. J Assoc Physicians India. 2008;56:759-762.

Copyright: (C) the author(s), 2020. It is an open-access article distributed under the terms of the Creative Commons Attribution License (CC BY 4.0), which permits authors to retain ownership of the copyright for their content, and allow anyone to download, reuse, reprint, modify, distribute and/or copy the content as long as the original authors and source are cited.

How to cite this article: Kulkarni MR. Assessment of Serum Uric Acid Levels in Patients with Acute Myocardial Infarction. Acad. J Med. 2020;3(2):46-48.

DOI: dx.doi.org/10.47008/ajm.2020.3.2.11

Source of Support: Nil, Conflict of Interest: None declared. 